\title{
Understanding p300-transcription factor interactions using sequence variation and hybridization
}

Fruzsina Hobor, ${ }^{a, b}$ Zsofia Hegedus, ${ }^{c *}$ Amaurys Avila Ibarra, ${ }^{\text {de }}$ Vencel L. Petrovicz, ${ }^{c}$ Gail J. Bartlett, ${ }^{d, e, f}$ Richard B. Sessions, ${ }^{d, e}$ Andrew J. Wilson, ${ }^{a, g *}$ and Thomas A. Edwards ${ }^{a, b *}$

aAstbury Centre for Structural Molecular Biology, University of Leeds, Woodhouse Lane, Leeds LS2 9JT, UK

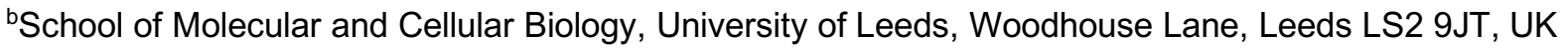
'Department of Medical Chemistry, University of Szeged, Dóm tér 8, H-6720 Szeged, Hungary

${ }^{d}$ School of Biochemistry, University of Bristol, Medical Sciences Building, University Walk, Bristol BS8 1TD, UK

eBrisSynBio, University of Bristol, Life Sciences Building, Tyndall Avenue, Bristol BS8 1TQ, UK

${ }^{f}$ School of Chemistry, University of Bristol, Cantock's Close, Bristol BS8 1TS, UK

9School of Chemistry, University of Leeds, Woodhouse Lane, Leeds LS2 9JT, UK

*e-mail: hegedus.zsofia@med.u-szeged.hu, $\underline{\text { a.j.wilson@leeds.ac.uk, t.a.edwards@leeds.ac.uk }}$

\begin{abstract}
The hypoxic response is central to cell function and plays a significant role in the growth and survival of solid tumours. HIF-1 regulates the hypoxic response by activating over 100 genes responsible for adaptation to hypoxia, making it a potential target for anticancer drug discovery. Although there is significant structural and mechanistic understanding of the

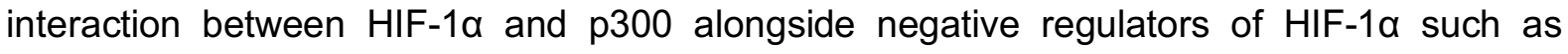
CITED2, there remains a need to further understand the sequence determinants of binding. In this work we use a combination of protein expression, chemical synthesis, fluorescence anisotropy and isothermal titration calorimetry for HIF-1 $\alpha$ sequence variants and a HIF-1 $\alpha-$ CITED hybrid sequence which we term CITIF. We show the HIF-1a sequence is highly tolerant to sequence variation through reduced enthalpic and less unfavourable entropic contributions, These data imply backbone as opposed to side chain interactions and ligand folding control the binding interaction and that sequence variations are tolerated as a result of adopting a more disordered bound interaction or "fuzzy" complex.
\end{abstract}




\section{Abbreviations list}

$\begin{array}{ll}\text { ALA scan } & \text { Alanine scan } \\ \text { BUDE } & \text { Bristol University Docking Engine } \\ \text { C-TAD } & \text { Carboxy-terminal transactivation domain } \\ \text { FA } & \text { Fluorescence Anisotropy } \\ \text { GFP } & \text { Green Fluorescent Protein } \\ \text { GST } & \text { Glutathione S-transferase } \\ \text { HIF-1 } & \text { Hypoxia-inducible factor 1-alpha } \\ \text { ITC } & \text { Isothermal titration calorimetry } \\ \text { mAV } & \text { multiple alanine variant } \\ \text { NMR } & \text { Nuclear magnetic resonance } \\ \text { PPI } & \text { Protein-protein interaction } \\ \text { SAV } & \text { Single alanine variant } \\ \text { wt } & \text { wild type }\end{array}$




\section{Introduction}

The hypoxic response is crucial to cell survival; it needs to both rapidly adapt to subtle variations in, and fluctuating, oxygen levels, and, allow recovery from hypoxia. ${ }^{1-3}$ As low oxygen level is a universal hallmark of solid tumours, the ability to adapt to hypoxia is essential for their growth and survival. ${ }^{4}$ The hypoxic response is mediated by transcriptional activation of genes that facilitate either short term (e.g. increased vascular permeability, glucose transport) or long term adaptive mechanisms (such as angiogenesis); ${ }^{5-7}$ these processes are largely mediated by the transcription factor Hypoxia Inducible factor (HIF) $1 .^{5-7}$ HIF-1 is responsible for the activation of over 100 genes that play essential roles in the hypoxic response and thus plays a role in tumour growth and survival, making it a potential target for anticancer drug discovery. ${ }^{8-12}$ Indeed, a number of approaches to target protein-protein interactions of HIF-1 have been explored. ${ }^{11,13-24}$ HIF-1 is a heterodimer, consisting of two subunits, the constitutively expressed HIF-1 $\beta$ and the oxygen sensitive HIF-1 $1{ }^{3}$ Under normoxic conditions, HIF-1 $\alpha$ undergoes hydroxylation leading to interaction with the E3 Ligase $\mathrm{pVHL}$ and degradation, whereas under hypoxic conditions this is suppressed resulting in accumulation and translocation of HIF- $1 \alpha$ to the nucleus where it forms a heterodimer with HIF-1 $\beta$ and recruits transcriptional co-activators, such as $p 300 .{ }^{8,25-30}$ The multidomain protein p300 and its paralogue CREB binding protein (CBP) are very similar in structure; they comprise a number of domains including the nuclear interaction domain ( $\mathrm{Nu}$ ), the CREB and MYB interaction domain (KIX), cysteine/histidine regions ( $\mathrm{CH} / \mathrm{TAZ})$, a histone acetyltransferase domain (HAT) and a bromodomain $(\mathrm{Br}){ }^{31-32} \mathrm{The} \mathrm{CH} 1$ domain (which differs by only a few amino acids between p300 and CREB ${ }^{33-34}$ interacts with the C-TAD of HIF-1 $\alpha$. The $\mathrm{CH} 1$ domain has been shown to interact with a number of transcription factors including HIF-1 $\alpha,{ }^{28,}{ }^{33}$ CREB-binding protein/p300-interacting transactivator with ED-rich tail (CITED 2), ${ }^{35-36} \mathrm{p} 53,{ }^{37} \mathrm{NF}-\mathrm{kB}$ p65 subunit RelA, ${ }^{38}$ and, signal transducer and activator of transcription 2 (STAT2) ${ }^{39}$ through a range of recognition modes. ${ }^{40}$ Of particular interest, CITED2, is a negative feedback regulator that reduces HIF-1 transcriptional activity by competing for p300/CBP. ${ }^{41-45}$ HIF-1 $\alpha$ and CITED2 have been reported to operate via a hypersensitive regulatory switch that exploits the properties of intrinsic disorder, similar p300/CBP binding affinities and a common $\mathrm{LP}(\mathrm{Q} / \mathrm{E}) \mathrm{L}$ sequence mechanistically essential for binding, flanked by helical regions. CITED2 has been reported to displace HIF-1 $\alpha$ from the surface of p300/CBP via transient ternary complex formation with both $\mathrm{p} 300 / \mathrm{CBP}$ and HIF-1a followed by a subsequent shift in conformation resulting in a kinetic lock and prevention of the reverse process (i.e. displacement of CITED2 by HIF-1 $\alpha$ ). ${ }^{46-47}$ This provides a rationale as to why HIF$1 \alpha$ transcriptional activity is sensitive to moderate CITED concentrations ${ }^{41}$ allowing effective negative feedback. 
HIF-1a interacts with p300/CBP via its carboxy terminal transactivation domain (CTAD). The solution structure of HIF-1a C-TAD in complex with p300/CBP was previously determined by NMR. ${ }^{28,33}$ The $\mathrm{CH} 1$ domain of p300/CBP forms a rigid globular structure consisting of four $\alpha$-helices (referred to here as $\alpha_{1-4}$ ), stabilised and constrained by three $\mathrm{Zn}$ atoms. The isolated C-TAD domain of HIF-1 $\alpha$ is disordered in the absence of its binding partner. When bound to p300/CBP the HIF-1a C-TAD consists of three distinct $\alpha$-helical regions and wraps around the p300/CBP CH1 domain ${ }^{28}$ (Fig. 1c-d, note in structure PDB ID: $1 \mathrm{~L}^{3} \mathrm{E}^{33}$ the $\mathrm{N}$-terminal region does not adopt a helical conformation). Several studies provide contradictory conclusions as to the importance of various regions and residues on HIF-1a CTAD for p300/CBP. ${ }^{17,} 19,48-49$ Mutational studies proposed key binding residues of HIF-1a; ${ }^{48}$ the $N$-terminal helix (HIF-1 $\alpha_{782-790}$, also referred to as HIF-1 $\alpha \alpha_{A}$ ) has been shown to be less important for p300/CBP binding whilst the central and C-terminal helices (HIF-1 $\alpha_{797-805}$ and HIF-1 $\alpha_{815-826}$, also referred to as HIF-1 $\alpha \alpha_{B}$ and HIF- $1 \alpha \alpha_{C}$ respectively) of the HIF-1 $\alpha$ C-TAD have been shown to be required for p300 recognition. ${ }^{50} \mathrm{HIF}-1 \alpha_{797-805}$ bears two residues, Cys800 and Asn803, which can undergo post-translational modifications that modulate binding, ${ }^{15,49,51-52}$ and HIF-1 $\alpha_{815-826}$ helix residues Leu818, Leu822 and Val825 are also considered important for binding. ${ }^{48}$ Additional HIF- $1 \alpha_{815-826}$ helix residues that have been suggested to be important for recognition, include Asp823 and GIn824. ${ }^{17}$, 19 The potency of sequences derived from HIF-1 $\alpha$ C-TAD (HIF-1 $\alpha_{776-826}$, HIF-1 $\alpha_{786-826}$ HIF-1 $\alpha_{788-822}$ HIF-1 $\alpha_{776-813}$ ) binding to $\mathrm{p} 300 / \mathrm{CBP}$ were compared using fluorescence polarization. ${ }^{49}$ From this experiment it was concluded that the C-terminus of HIF-1a C-TAD is important for binding, in agreement with the mutagenesis studies. ${ }^{33,48}$ Moreover, p300 sequence variants within the region that binds HIF-1 $\alpha_{815-826}$ highlight its importance: whilst His349Ala and Leu376Met p300 variants showed minimal difference in HIF-1a affinity, a significant drop in potency was observed for the lle400Met p300 variant; ${ }^{50}$ all these variants are found within the HIF-1 $\alpha_{815-826}$ binding region with Ile400 closest to HIF-1 $\alpha_{815-826}$. Site-directed mutagenesis in combination with kinetics measurements have been used to study the transition state for binding p300/CBP and the HIF-1 $\alpha$ C-TAD: 17 HIF-1 $\alpha$ C-TAD sequence variants were generated and binding assessed. $\Phi-V a l u e$ binding analysis suggested that native hydrophobic binding interactions do not form at the transition state. ${ }^{53} \mathrm{HIF}-1 \alpha$ Asn-803 hydroxylation was also shown to have a minimal destabilization effect. These data suggest the rate-limiting transition state is "disordered-like", with subsequent co-operative formation of native binding contacts and replicates results observed for other p300/CBP CH1 interactions. ${ }^{54}$

HIF-1a (residues 776-826) and CITED2 (residues 216-269) recognize partially overlapping binding sites on p300/CBP (Fig. 1d-f). The helices of HIF-1 $\alpha$ and CITED2 and their conserved $L P(Q / E) L$ motifs bind to the same surfaces of the $\mathrm{p} 300 / \mathrm{CBP} C H 1$ domain. The 
region of CITED2 that is C-terminal to the LPEL motif binds in an extended conformation in the same site as the HIF-1 $\alpha_{797-805}$ helix. ${ }^{35-36}$ Despite this significant structural and mechanistic understanding of transcription factor p300/CBP interactions, there is a need to further understand the determinants of binding at a sequence level. Motivated by our recent studies on the effects of the HIF-1 $\alpha$ truncation on the HIF-1 1 /p300 interaction, ${ }^{21,50}$ identification of peptide and non-antibody binding proteins through selection methods, ${ }^{50}$ and, development of designed HIF-1 $\alpha /$ p300 inhibitors ${ }^{18,21,23,55}$ we sought to understand those determinants. We used a combination of protein expression, chemical synthesis, fluorescence anisotropy and isothermal titration calorimetry to probe the binding of HIF-1 $\alpha$ sequence variants, CITED2 and a HIF-1a-CITED2 hybrid sequence (which we term CITIF; Fig. 1a) to the p300 $\mathrm{CH} 1$ domain (residues 330-420, hereinafter referred as p300). Our results point to an interaction that is remarkably tolerant to sequence variation, despite a high degree of sequence conservation across species. ${ }^{28}$ The parent interaction is enthalpically very favourable and entropically unfavourable; it seems to tolerate sequence variation through reduced enthalpic and less unfavourable entropic contributions, features which support a hypothesis whereby interactions between ligand (HIF-1 $\alpha$ ) and protein (p300) exploit a combination of non-covalent contacts between the HIF-1 $\alpha$ backbone (as opposed to side-chains) and the surface of well folded p300 $\mathrm{CH} 1$ domain, along with HIF-1 $\alpha$ folding, driven by transient side-chain contacts and long range electrostatic interactions to derive binding free energy. Adopting a more disordered bound interaction or "fuzzy" complex is consistent with the observed changes in thermodynamic signature and might account for the broadly tolerated sequences. 
(a)

$$
\begin{aligned}
& \text { HIF-1 } \alpha_{776-826} \\
& \text { HIF-1 } \alpha_{786-826} \\
& \text { CITED2 } 2_{216-269} \\
& \text { CITED2 } 2244-259
\end{aligned}
$$

CITIF

(b)

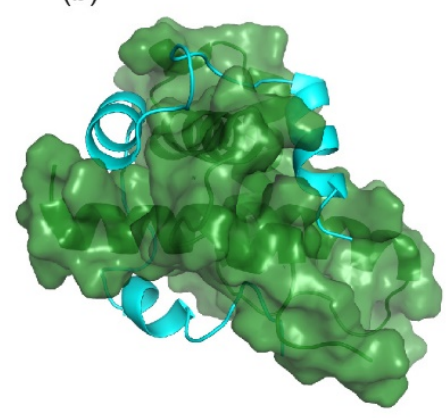

(c) $H \mathrm{HF}-1 \alpha_{797-805}\left(\alpha_{\mathrm{B}}\right)$

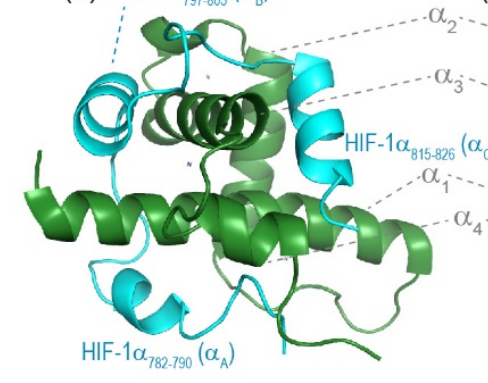

(d)

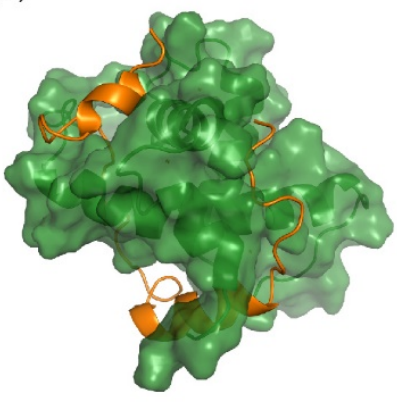

(e)

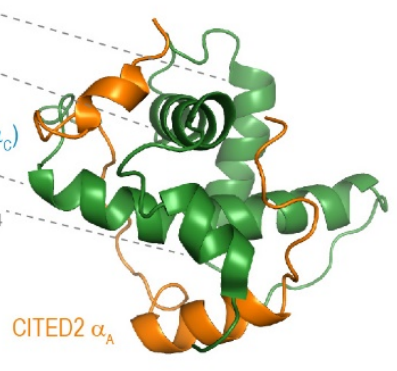

SDLACRLLGOSMDESGLPOLTSYDCEVNAPIOGSRNLLQGEELLRALDOVN

DEEVLMSLVIEMGLDRIKELPQLTSYDCEVNAPIQGSRNLLQGEELLRALDQVN

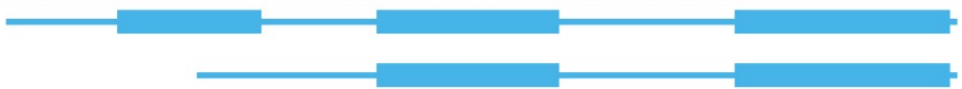

(f)
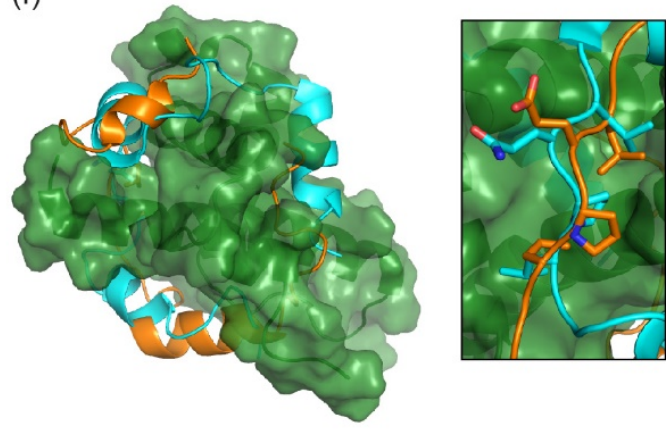

(g)

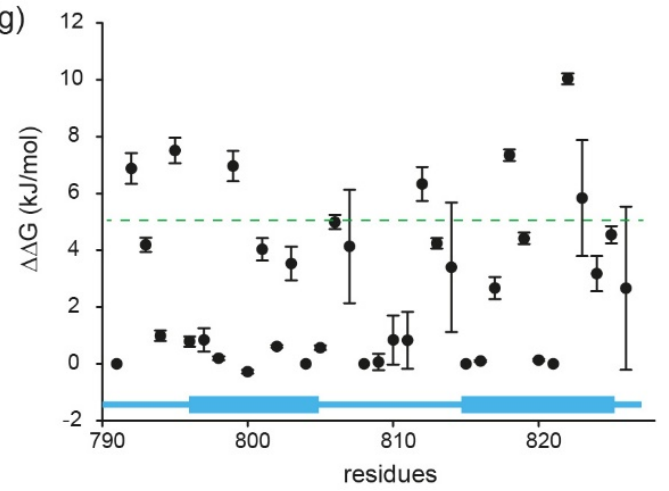

Figure 1. Sequences and structures of the p300 transcription factor complexes investigated in this work and binding free energy predictions on sequence determinants. (a) Sequence variants of HIF-1 $\alpha$ and CITED2, helical regions are indicated by rectangles under the sequences. (b) Lowest energy structure from an NMR derived ensemble of the HIF-1 $\alpha$ CTAD (cyan fold) and $\mathrm{CBP}$ (p300) $\mathrm{CH} 1$ domain (green surface) interaction (PDB ID: 1L8C); (c) same structure with HIF-1 $\alpha$ C-TAD (cyan fold) and $\mathrm{CBP}(\mathrm{p} 300) \mathrm{CH} 1$ domain (green fold); key regions are annotated for both HIF-1 $\alpha$ and p300 with corresponding nomenclature used in Appling et al. ${ }^{47}$ for clarity; (d) lowest energy structure from an NMR derived ensemble of the CITED2 (orange fold) and $\mathrm{CBP}(\mathrm{p} 300) \mathrm{CH} 1$ domain (green surface) interaction (PDB ID: 1P4Q); (e) same structure with CITED2 (orange fold) and $\mathrm{CBP}(\mathrm{p} 300) \mathrm{CH} 1$ domain (green fold); key regions are annotated for both CITED2 and p300 with corresponding nomenclature used in Appling et al., ${ }^{47}$ for clarity; (f) overlay of the HIF-1 $\alpha$ C-TAD (cyan fold) and CITED2 (orange fold) interactions with $\mathrm{CBP}(\mathrm{p} 300) \mathrm{CH} 1$ domain (inset highlights the region where the conserved $\mathrm{LPE}(\mathrm{Q}) \mathrm{L}$ residues interact); (g) results of hot residue prediction using in silico 
alanine scanning (BUDE, 20 lowest energy structures from the NMR ensemble used in the prediction, circles denote average predicted $\Delta \Delta \mathrm{G}$, error bars the standard deviation).

\section{Results and Discussion}

\section{HIF-1a single sequence variations have little effect on p300 binding affinity}

We previously developed BUDE AlaScan as predictive tool to identify hot residues and experimentally validated it for $\alpha$-helix and $\beta$-strand mediated interactions. ${ }^{56-57}$ In those cases the interaction was localized within a single helix or strand in at least one of the interacting partners. The extended nature of the HIF-1a/p300 interaction afforded an opportunity to test the capabilities of in silico alanine scanning where affinity may be dispersed across a larger number of amino acid residues (for comparison, the NOXA/MCL-1 interaction has MCL-1 binding affinity $K_{D} \sim 100 \mathrm{nM}$ with 19 residues in NOXA as opposed to HIF-1 $\alpha$ with similar $K_{\mathrm{D}}$ but 42 residues). BUDE AlaScan can predict changes in $\Delta \Delta G$ of binding upon introducing single or multiple alanine variations in one of the interacting partners when compared to the binding energy of the wild-type protein; in this case for HIF-1 $\alpha$ using the HIF-1 $\alpha /$ p300 NMR derived ensemble (PDB ID: 1L8C). This analysis (Fig. 1g) predicted key determinants of the HIF-1a binding to be dispersed across the whole sequence with several residues in both HIF-1 $\alpha_{797-805}$ and HIF-1 $\alpha_{815-826}$ showing $\Delta \Delta G>4.2 \mathrm{~kJ} / \mathrm{mol}$ (the threshold for a hot residue). ${ }^{57-59}$ A number of these e.g. $L 792$ and $L 822$ show $\Delta \Delta G>4.2 \mathrm{~kJ} / \mathrm{mol} \Delta \Delta G$ with small standard deviation implying those positions are indeed important for p300 binding while other residues with smaller values and greater standard deviation, like D823 were less clear cut. ROBETTA ${ }^{60}$ provided similar data (see ESI, Fig. S1).

To experimentally compare the predictions, we carried out an in vitro biophysical study of several HIF-1a sequence variants. We assessed predicted hot residues and their interactions with p300 using the NMR structure to visualize the structural basis behind the predictions (See ESI, Fig. S2). These analyses helped refine a first series of alanine variants to prepare. We did not consider HIF-1 $\alpha_{782-790}$ variants given prior studies which had established little overall effect from the presence/absence of these 8-10 residues. ${ }^{50} \mathrm{HIF}-1 \alpha_{776}$ 826 sequence variants were recombinantly prepared based on the predictions to test their binding to the recombinantly prepared p300 (Fig. 2). Given the length of the peptide (42 residues), this was considered advantageous as it obviates the need to chemically synthesise, label and purify multiple variants. As the C-TAD domain is unstructured in isolation it was recombinantly expressed as a fusion protein with GFP. The green-fluorescent protein (GFP) tag was used for fluorescence anisotropy experiments to determine the binding affinity of HIF$1 \alpha_{776-826} \mathrm{C}-\mathrm{TAD}$ variants to $\mathrm{p} 300$. As the $\mathrm{CH} 1$ domain of $\mathrm{p} 300$ is a small domain of $11 \mathrm{kDa}$ it 
was recombinantly expressed as a fusion protein with GST to increase its size and thus the signal to noise in the FA experiments. We established an assay where the interaction between GFP-tagged wt HIF-1 $\alpha_{776-826}$ and GST-tagged p300 was monitored by FA, using the fluorescence of GFP. As GST dimerises, we assume the stoichiometry of the interaction is 2:2. (Fig. 2a). To demonstrate that binding between HIF-1 $\alpha$ and p300 was not affected by GST a control experiment was performed using GFP-HIF-1 $\alpha_{776-826}$ and p300 with the GST tag cleaved; although the change in anisotropy signal was lower (consistent with the lower mass of the complex in the absence of GST) the determined $K_{\mathrm{D}}$ was comparable between the two experiments (Fig. S3). Similarly, ITC experiments for the binding of GFP-HIF-1 $\alpha_{776-826}$ and HIF$1 \alpha_{776-826}$ to $\mathrm{p} 300$ were comparable (see later).

(a)

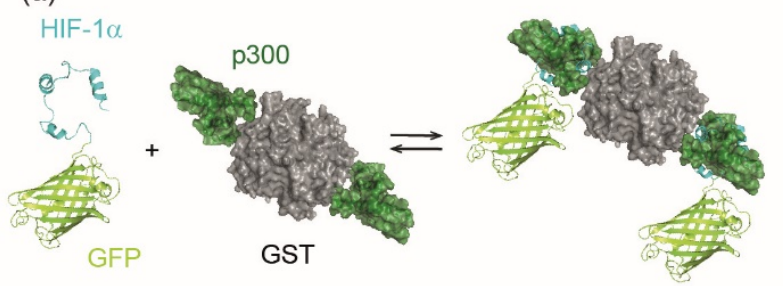

(b)
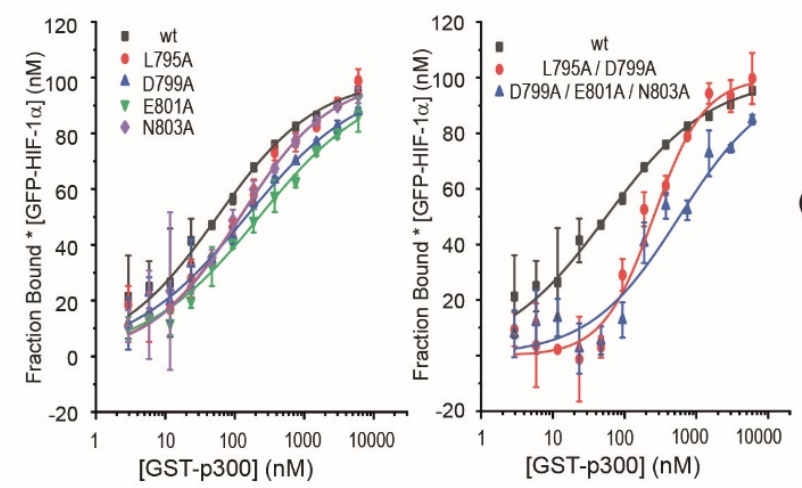

(c)

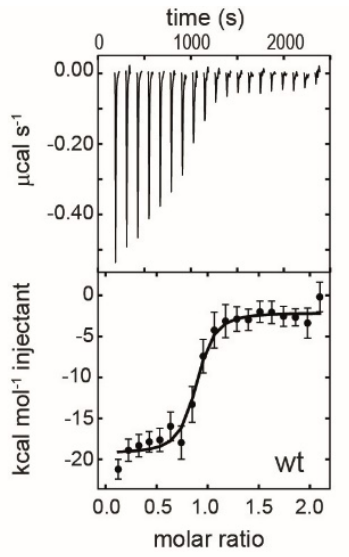

(d)

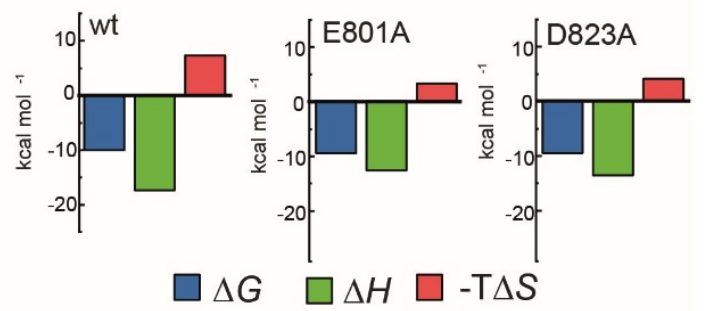

Figure 2. Biophysical analyses on the effects of HIF-1a sequence variant p300 binding affinity. (a) schematic depicting the equilibrium for interaction of GFP-HIF-1 $\alpha_{776-826}$ variants and GSTp300 as studied by fluorescence anisotropy; (b) representative fluorescence anisotropy titration data for sAV and mAV HIF-1 $\alpha_{776-826}$ peptides interacting with p300 (25 mM Tris-HCl, $150 \mathrm{mM} \mathrm{NaCl}, 1 \mathrm{mM}$ DTT, $p H$ 7.4); (c) raw ITC data (upper) and fitted thermogram (lower) for the interaction of HIF-1 $\alpha_{776-826}$ peptides with p300 $\left(37^{\circ} \mathrm{C}\right.$ in $25 \mathrm{mM} \mathrm{Tris-HCl,} 150 \mathrm{mM} \mathrm{NaCl}$,

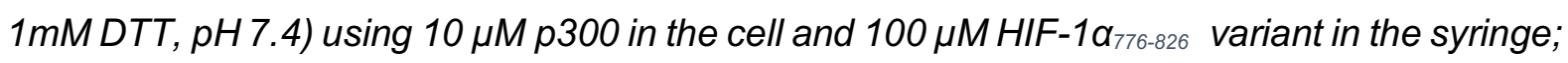
(d) thermodynamic signatures for each interaction.

After establishing the assay, selected single alanine HIF-1a CTAD variants (sAVs) were prepared and their binding affinity to p300 was tested. Results for these experiments are shown in Figure 2b, Table 1 and Fig. S4. Our data show there is a limited impact upon the 
binding to p300 for single alanine variations introduced into HIF-1 $\alpha_{797-805}$, HIF-1 $\alpha_{815-826}$ or the LPQL sequence that shares homology with CITED2 ( $\leq 4$ fold maximal difference). This contrasts with the work of Lindström who identified L792A, L795A and L818A as hot residues (alongside L812A and L813A, which were not considered here), although these were derived from $\Phi$-value binding analysis using tryptophan fluorescence and may reflect transition state effects upon binding.

Table 1. Dissociation constants for HIF-1 $\alpha_{776-826} \mathrm{C}-\mathrm{TAD}$ single alanine mutant variants binding to $\mathrm{p} 300$

\begin{tabular}{|c|c|c|c|}
\hline HIF-1 $\boldsymbol{\alpha}$ SAV variant & $\boldsymbol{K}_{\boldsymbol{D}}(\mathbf{n M})$ & HIF-1 $\boldsymbol{\alpha}$ MAV variant & $\boldsymbol{K}_{\boldsymbol{D}}(\mathbf{n M})$ \\
\hline wt & $55 \pm 27$ & L795A D799A & $255 \pm 44$ \\
\hline L795A & $118 \pm 19$ & D799A E801A N803A & $590 \pm 302$ \\
\hline S797A & $37 \pm 16$ & L818A L822A & $126 \pm 33$ \\
\hline D799A & $114 \pm 53$ & L818A L822A D823A & $247 \pm 75$ \\
\hline E801A & $227 \pm 78$ & L818A L822A V825A & $54 \pm 33$ \\
\hline N803A & $120 \pm 17$ & E801A L822A & $224 \pm 18$ \\
\hline E817A & $128 \pm 11$ & L795A D799A L822A & $174 \pm 45$ \\
\hline L818A & $237 \pm 40$ & $\begin{array}{c}\text { L795A D799A L818A } \\
\text { L822A V825A }\end{array}$ & $153 \pm 19$ \\
\hline L822A & $109 \pm 66$ & & \\
\hline D823A & $192 \pm 17$ & & \\
\hline Q824A & $31 \pm 8$ & & \\
\hline V825A & $198 \pm 37$ & & \\
\hline
\end{tabular}

${ }^{a}$ conditions as in Figure $2 b$

We carried out ITC measurements for several variants to verify the results of the fluorescence anisotropy measurements (Fig. 2c and ESI, Fig. S5). The interaction of HIF$1 \alpha_{776-826}$ with p300 is characterized by a large favourable enthalpy of interaction and opposing unfavourable entropy of interaction. The dissociation constant was similar for all the tested variants and the thermodynamic signature shifted toward less favourable enthalpic contributions compensated by more favourable entropy (Figure 2c-d, Table 2.) The removal of a transient charge reinforced interaction (E801A and D823A) may increase the local flexibility of the structure resulting in the observed, less unfavourable entropy. This implies that HIF-1 $1 \alpha$ can adjust its interaction with p300 to achieve optimal affinity also for the variants, which emphasizes the requirement to occupy the surface through 'fuzzy' interactions rather than specific contacts. 
Table 2. Thermodynamic parameters for the binding of GFP-HIF-1 $\alpha_{776-826}$ variants to $p 300$. $68 \%$ confidence intervals are shown in brackets (conditions as in Figure 2c)

\begin{tabular}{|c|c|c|c|}
\hline a & $K_{\mathrm{D}} \mathrm{nM}$ & $\begin{array}{c}\Delta H \\
\mathrm{kcal} \mathrm{mol}^{-1}\end{array}$ & $\begin{array}{c}\Delta S \\
\text { cal } \mathrm{mol}^{-1} \mathrm{~K}^{-1}\end{array}$ \\
\hline HIF-1 $1 \alpha$ & $\begin{array}{c}86 \\
(32-182)\end{array}$ & $\begin{array}{c}-17.3 \\
(-18.1 \text { to }-16.6)\end{array}$ & -23.6 \\
\hline HIF-1 $\alpha$ E801A & $\begin{array}{c}359 \\
(284-444)\end{array}$ & $\begin{array}{c}-12.2 \\
(-12.6 \text { to }-11.9)\end{array}$ & -9.5 \\
\hline HIF-1aD823A & $\begin{array}{c}369 \\
(264-496)\end{array}$ & $\begin{array}{c}-13.0 \\
(-12.5 \text { to }-13.6)\end{array}$ & -12.2 \\
\hline
\end{tabular}

a we also prepared an L792A variant which exhibited $\mathrm{nM}$ affinity although the quality of data fitting impedes a more detailed analyses of thermodynamic parameters in this instance (see Figure S5).

\section{HIF-1a multiple sequence variations do not affect p300 binding affinity}

To assess the extent to which sequence variations could confer additive effects on binding affinity, different, structurally relevant combinations (i.e. with the highest combined predicted $\Delta \Delta G$ values) of alanine variations were introduced into the HIF-1 $\alpha_{776-826}$ C-TAD and their binding affinity determined (Fig. 3, Table 1 and ESI Fig. S4). The experimental data for these multiple alanine variants (mAVs) clearly shows that variations of two or three predicted hot residues either in HIF-1 $\alpha_{797-805}$ or HIF-1 $\alpha_{815-826}$ are generally insufficient to abrogate p300 binding. Even introducing variations in two helices (e.g. E801A L822A) simultaneously did not increase the $K_{\mathrm{D}}$ significantly; variants generally maintained affinity to p300 although for some mAVs (e.g., D799A-E801A-N803A; L795A-D799A; L818A-L822A-D823A and E801A L822A), there appears to be some loss in potency. Lower net negative charge of the TADs influences the long-range electrostatic interactions leading to lower association rates, ${ }^{61}$ which, in part may explain the decreased binding affinity of some of these mAVs. Collectively, these data further support a conclusion that the HIF-1 $/$ /p300 interface is fuzzy in nature; the plasticity in the interaction allows for signficiant sequence variation in the HIF-1 $\alpha$ C-TAD with loss of one side chain likely to be compensated for by interactions of other side chains, possibly augmented by interactions of the backbone with the p300 surface.

\section{Comparison of predicted and experimental variant HIF-1 $\alpha /$ p300 binding affinities}

The experimental determined values for $\mathrm{SAV} s$ and $\mathrm{mAV} s$ do not agree fully with the predictions (Fig 3). It should be noted that the predictions (both using BUDE and ROBETTA) did not identify particularly large sAV $\Delta \Delta \mathrm{G}$ values $>8 \mathrm{~kJ} \mathrm{~mol}^{-1}$ and our earlier work highlighted the 
challenges in accurately predicting absolute values of $\Delta \Delta G$ using fast methods which are well suited to a yes/no indicator. ${ }^{56-57}$ Overall, the comparison between prediction and experiment for sAVs reveals the predictions overestimate the change in affinity, although there is still a moderate effect for most predicted hot-residues. Comparison of the prediction and experiment for mAVs reveals more pronounced differences; the additive combination of sequence variations is predicted to be significant ( $>15 \mathrm{~kJ} / \mathrm{mol}$ in many cases), yet minimal effects are observed for as many as five simultaneous sequence variations. This is consistent with the interaction becoming more fuzzy upon sequence variation to compensate for loss of sidechain interactions, a property not assessed in predictive alanine scanning.

Taken together our results suggest that interaction of some of the side-chains from each helix of HIF-1 $\alpha$ are sufficient to maintain nanomolar affinity for p300; as the three helices wrap around p300; varying one or two positions is not sufficient to disrupt the binding, implying a high degree of chelate co-operativity (observed in our earlier truncation studies) ${ }^{50}$ and dispersal of binding energy across the sequence. As noted above for the thermodynamic analyses, the large favourable enthalpy and unfavourable entropy of binding for the native HIF-1 1 /p300 interaction together with the well tolerated sequence variation and observed enthalpy-entropy compensation for variants predicted to have diminished p300 affinity points to a key role of backbone or long range electrostatic interactions (which are not explored using computational alanine scanning) and transcription factor folding to generate binding energy. Such behaviour and any potential decrease of unfavourable steric contacts would accommodate sequence variation where the variant bound complex is more disordered relative to the native bound complex.

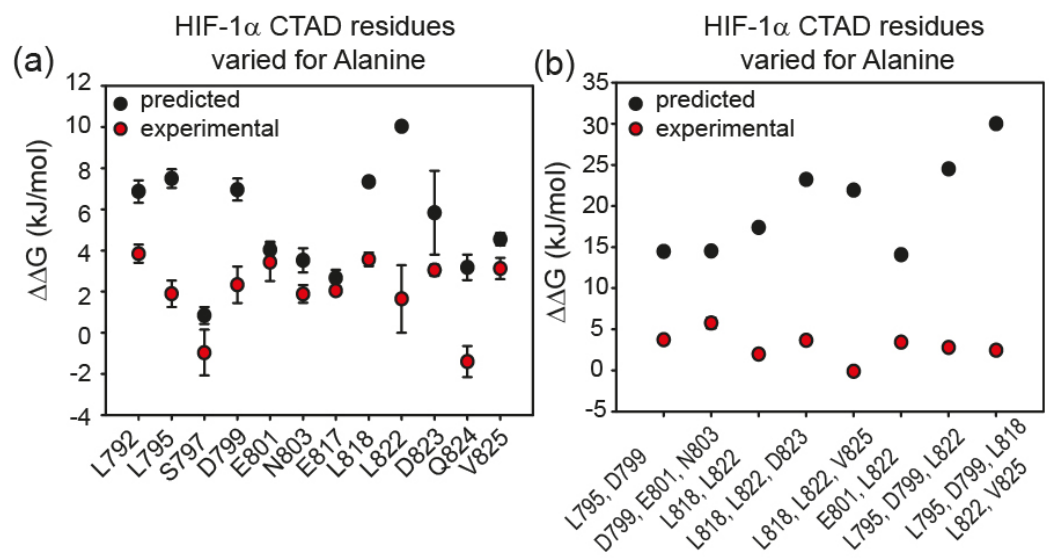

Figure 3 Comparison of predicted and experimental $\Delta \Delta G$ values for: (a) single alanine variant (sAV) and (b) multiple alanine variants of HIF-1a C-TAD for binding to $p 300 . \Delta \Delta G$ values were derived from FA measurements, except for L792A for which ITC data was used. 


\section{CITED2 has higher affinity than HIF-1a for p300 and exhibits a sequence dependent competition mechanism}

We hypothesized that it would be possible to enhance the affinity of HIF-1 $\alpha$ for p300 by hybridising key regions of both CITED2 and HIF-1a (see later). We first measured the affinity of the parent peptides. A particular difficulty in comparing these peptide sequences is the different length used in different studies. ${ }^{28,33,35-36}$ We therefore considered HIF-1 $\alpha_{786-826}$, HIF$1 \alpha_{776-826}$ CITED2 $224-259$ and CITED2 $216-269$ for these analyses and studied binding to p300 using ITC. Initially we expressed these as GFP fusion proteins and cleaved the tag, however the peptides all contained four residues from the PreScission protease sequence (ITC data given in the ESI Fig. S6).

Subsequently we also developed a chemical synthesis of the peptides bearing an $\mathrm{N}$ terminal acetamide and C-terminal amide (see ESI). In general both sets of reagents gave similar data in terms of $K_{D}$ - one notable exception is CITED $224-259$ which gave a $K_{D}$ four-fold lower in magnitude for the expressed peptide relative to the chemically synthesized peptide. It may be that the four residues (Gly-Pro-Gly-Ser) remaining from the Prescission protease cleavage or free $\mathrm{N}$-terminus interfere with p300 recognition. Support for this hypothesis is strengthened by the fact that both HIF-1 $\alpha$ sequences also have weaker affinity (although not as pronounced) in comparison to the synthetic peptides. Overall, the CITED2 peptides have slightly higher p300 affinity than the HIF-1a peptides. This differs from observations reported by Berlow et al. who observed identical $K_{D}$ S of $10 \mathrm{nM}$ for HIF-1 $\alpha_{776-826}, 10 \mathrm{nM}$ CITED2 $216-269$ both labelled with Alexafluor 488/595. In this prior work, a variety of biophysical and NMR methods were used to show that despite similar potencies, CITED2 effectively displaces HIF$1 \alpha$ from the surface of p300 via transient ternary complex formation with both p300 and HIF$1 \alpha$ followed by a subsequent shift in conformation resulting in a kinetic lock and suppression of the reverse process (i.e. displacement of CITED2 by HIF-1 $\alpha$ ). ${ }^{46}$ Although the NMR experiments were performed at higher concentration, the fluorescent experiments used to determine affinity were performed at lower concentrations; the fluorescent labels and their positions may influence the equilibrium. The ITC data on unlabelled peptides which we report here suggest that the moderate preference for interaction of CITED2 with p300 over HIF-1 $\alpha$ may incorporate a thermodynamic aspect and not exclusively derive from kinetic factors. 

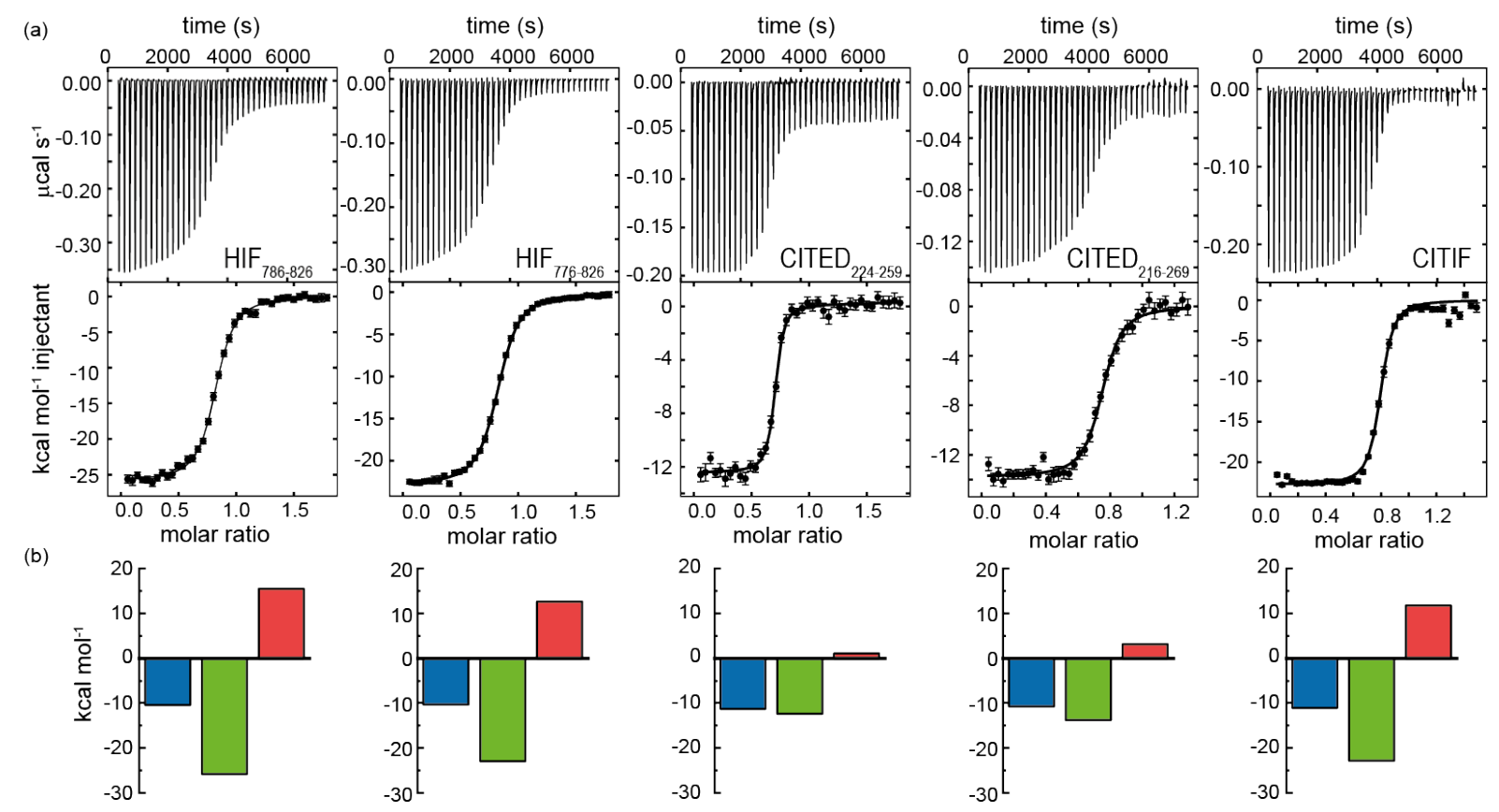

$\Delta G \quad \square \Delta H \square-T \Delta S$

Figure 4. (a) Isothermal titration calorimetry data for the interaction of chemically synthesized HIF-1a, CITED2 and CITIF peptides with p300. Raw ITC (upper) data and fitted thermogram (lower) (40 mM sodium phosphate, pH 7.5100 mM NaCl, 1 mM DTT buffer using $5 \mu$ M protein in the cell and $60 \mu \mathrm{M}$ ligand in the syringe at $35^{\circ} \mathrm{C}$ ); (b) Thermodynamic signatures for each interaction.

Table 3. Thermodynamic parameters for the binding of HIF-1a, CITED2 and CITIF peptides to $\mathrm{p} 300$

\begin{tabular}{|c|c|c|c|c|c|c|}
\hline & \multicolumn{3}{|c|}{ Synthetic Peptides ${ }^{a}$} & \multicolumn{3}{|c|}{ Expressed Peptides $^{b}$} \\
\hline & $K_{\mathrm{D}}(\mathrm{nM})$ & $\begin{array}{c}\Delta \mathrm{H} \\
\mathrm{kcal} \mathrm{mol}^{-1}\end{array}$ & \begin{tabular}{|c|}
$\Delta \mathrm{S}$ \\
$\mathrm{cal} \mathrm{mol}^{-1} \mathrm{~K}^{-1}$
\end{tabular} & $K_{\mathrm{D}}(\mathrm{nM})$ & $\begin{array}{c}\Delta \mathrm{H} \\
\mathrm{kcal} \mathrm{mol}^{-1}\end{array}$ & $\begin{array}{c}\Delta S \\
\text { cal } \mathrm{mol}^{-1} \mathrm{~K}^{-1}\end{array}$ \\
\hline $\mathrm{HIF-1} \alpha_{786-826}$ & $\begin{array}{c}42.9 \\
(38.3-47.6)\end{array}$ & $\begin{array}{c}-25.8 \\
(-25.6 \text { to }-26.1)\end{array}$ & -50 & $\begin{array}{c}88.3 \\
(57.0-132.4)\end{array}$ & $\begin{array}{c}-32.7 \\
(-31.5 \text { to }-33.9)\end{array}$ & -73.2 \\
\hline HIF-1 $\alpha_{776-826}$ & $\begin{array}{c}52.2 \\
(49.2-55.8)\end{array}$ & $\begin{array}{c}-22.9 \\
(-22.8 \text { to }-23.1)\end{array}$ & -41 & $\begin{array}{c}82.4 \\
(55.0-119.5)\end{array}$ & $\begin{array}{c}-22.2 \\
(-21.5 \text { to }-22.9)\end{array}$ & -39.2 \\
\hline CITED $_{224-259}$ & $\begin{array}{c}9.1 \\
(6.5-12.2)\end{array}$ & $\begin{array}{c}-12.4 \\
(-12.2 \text { to }-12.7)\end{array}$ & -3.6 & $\begin{array}{c}41.9 \\
(28.9-59.5)\end{array}$ & $\begin{array}{c}-12.4 \\
(-12.0 \text { to }-12.7)\end{array}$ & -6.2 \\
\hline CITED $_{216-269}$ & $\begin{array}{c}26.3 \\
(20.8-33.1)\end{array}$ & $\begin{array}{c}-13.2 \\
(-12.9 \text { to }-13.4)\end{array}$ & -10.0 & $\begin{array}{c}18.8 \\
(12.2-27.6)\end{array}$ & $\begin{array}{c}-13.3 \\
(-13 \text { to }-13.5)\end{array}$ & -7.5 \\
\hline CITIF & $\begin{array}{c}11.3 \\
(9.3-13.7)\end{array}$ & $\begin{array}{c}-22.5 \\
(-22.3 \text { to }-22.7)\end{array}$ & -37.8 & $\begin{array}{c}15.4 \\
(10.4-21.8)\end{array}$ & $\begin{array}{c}-18.3 \\
(-17.9 \text { to }-18.7)\end{array}$ & -23.3 \\
\hline
\end{tabular}

${ }^{a}$ conditions as in Figure 4

${ }^{\mathrm{b}}$ conditions as given in Figure S6

Competition experiments indicated that CITED2 and HIF-1 $\alpha$ bind with negative cooperativity to p300 with a mechanism depending on the length of the peptide (Fig. 5). The apparent $K_{\mathrm{D}}$ for $\mathrm{CITED}_{224-259}$ displacing $\mathrm{HIF}_{786-826}$ from p300 is $665 \mathrm{nM}(\Delta H=9.35 \mathrm{kcal} / \mathrm{mol})$ 
and for $\mathrm{HIF}_{786-826}$ in the reverse process is $4.2 \mu \mathrm{M}(\Delta H=-5.6 \mathrm{kcal} / \mathrm{mol})$, which is close to the expected values if the ligands bind competitively (Fig. S7, Table S1). Global analysis using a competitive binding model resulted in thermodynamic parameters that were concurrent with the direct titration experiments (Table 4.). On the other hand, CITED $216-269$ displaces HIF-1 $\alpha_{776-}$ 826 more effectively with an apparent $K_{\mathrm{D}}$ of $43 \mathrm{nM}(\Delta H=6.76 \mathrm{kcal} / \mathrm{mol})$ which indicated cooperative binding. This differs significantly from the value reported by Berlow et al.; they report that the apparent $K_{\mathrm{D}}$ for CITED2 against the p300/HIF-1 $\alpha=0.2 \mathrm{nM}$, a 50-fold lower value than $K_{\mathrm{D}}$ determined for the direct CITED2/p300 interaction. Global analysis of the ITC data suggested a ternary complex formation with a $\Delta \Delta G$ of $0.31 \mathrm{kcal} / \mathrm{mol}$ and $\Delta \Delta \mathrm{H} 20.5$ $\mathrm{kcal} / \mathrm{mol}$ (Table 4.) This data is consistent with the model where CITED2 and HIF-1 $\alpha$ bind simultaneously to p300 forming a ternary complex which is destabilized by unfavourable enthalpy change and compensated by favourable entropic contributions. The sequence dependence of the competition mechanism suggests that CITED2 $216-269$ contains the key residues that are responsible for the allosteric effect favouring unidirectional displacement of HIF-1 $\alpha$ by CITED2. This is supported by studies on a $C$ terminally truncated construct (CITED2 216-248), which despite having lower affinity to p300 $\left(K_{D}=303 \mathrm{nM}\right)$, displaces HIF-1 $\alpha_{776}$ 826 with similar efficiency to the higher affinity $\operatorname{CITED}_{224-259}\left(K_{\mathrm{d}, \text { app }}=2 \mu \mathrm{M}\right.$, Table S1-2). Furthermore, the removal of the $N$ terminal eight residues (CITED2224-248) results in significantly decreased affinity, highlighting the importance of these residues for binding (Figure S8, Table S2).

(a)

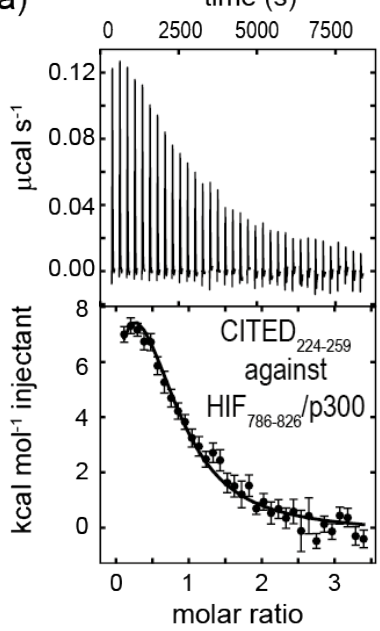

(b)

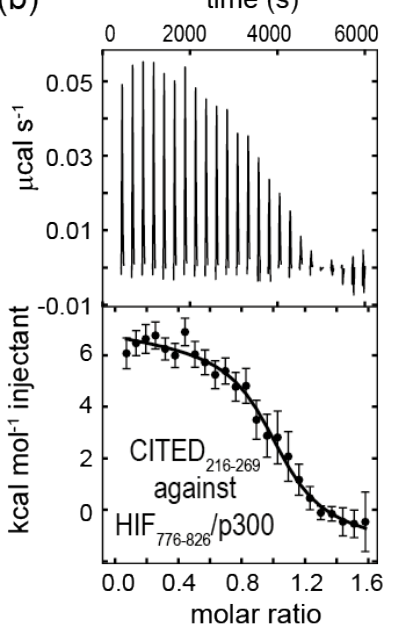

Figure 5 Competition ITC experiments (a) Raw ITC (upper) data and fitted thermogram (lower) for CITED2 $224-259$ titrated against the p300/HIF-1 $\alpha_{786-826}$ complex and (b) CITED2 216 269 titrated against the p300/HIF-1 $\alpha_{776-826}$ complex (40 mM sodium phosphate, pH $7.5100 \mathrm{mM}$ $\mathrm{NaCl}, 1 \mathrm{mM} D T T$ buffer at $\left.35^{\circ} \mathrm{C}\right)$. Complexes were prepared by titrating $p 300$ with the competitor ligand until it reached saturation, which resulted in 1.2-1.6 equivalent ligand in the 
cell. Concentrations and exact molar ratios are listed in Table S2. The thermograms were fitted globally including datasets for direct titrations.

Table 4 Thermodynamic parameters extracted from the global fitting of the competition titrations. The CITED2224-259 / HIF-1 $\alpha_{876-826}$ system was fitted using a competitive binding model, the CITED2 $216-269 / \mathrm{HIF}-1 \alpha_{776-826}$ system was fitted including a fit for $\Delta \Delta \mathrm{G}$ and $\Delta \Delta \mathrm{H} .68 \%$ confidence intervals are shown in brackets.

\begin{tabular}{|c|c|c|c|c|c|}
\hline & $K_{\mathrm{D}, \mathrm{nM}}$ & $\begin{array}{c}\Delta H \\
\mathrm{kcal} \mathrm{mol}^{-1}\end{array}$ & $\begin{array}{c}\Delta S \\
\text { cal } \mathrm{mol}^{-1} \mathrm{~K}^{-1}\end{array}$ & $\begin{array}{c}\Delta \Delta G \\
\mathrm{kcal} \mathrm{mol}^{-1}\end{array}$ & $\begin{array}{c}\Delta \Delta \mathrm{H} \\
\mathrm{kcal} \mathrm{mol}^{-1}\end{array}$ \\
\hline CITED $_{224-259}$ & $\begin{array}{c}8.2 \\
(9.3-7.1)\end{array}$ & $\begin{array}{c}-13.1 \\
(-13.3 \text { to }-12.9)\end{array}$ & -5.7 & \multirow[b]{2}{*}{ n.a. } & \multirow[b]{2}{*}{ n.a. } \\
\hline $\mathrm{HIF}_{786-826}$ & $\begin{array}{c}45.8 \\
(51.3-41.7)\end{array}$ & $\begin{array}{c}-24.6 \\
(-24.8 \text { to }-24.3)\end{array}$ & -46.2 & & \\
\hline CITED $216-269$ & $\begin{array}{c}26.9 \\
(33.8-21.4)\end{array}$ & $\begin{array}{c}-13.2 \\
(-13.4 \text { to }-13.0)\end{array}$ & -8.3 & \multirow{2}{*}{$\begin{array}{c}0.31 \\
(0.9 \text { to }-0.34)\end{array}$} & \multirow{2}{*}{$\begin{array}{c}20.5 \\
(19.9-21.2)\end{array}$} \\
\hline $\mathrm{HIF}_{776-826}$ & $\begin{array}{c}52.3 \\
(64.2-41.2)\end{array}$ & $\begin{array}{c}-22.9 \\
(-23.4 \text { to }-22.5)\end{array}$ & -41.1 & & \\
\hline
\end{tabular}

${ }^{a}$ conditions as in Figure 5

\section{A HIF-1 $\alpha$-CITED2 hybrid - CITIF - has comparable p300 binding affinity to CITED2, but exhibits intermediate enthalpic and entropic signature to those of the parent HIF-1 $\alpha$ and CITED2 sequences.}

A hybrid sequence (CITIF) was designed containing an N-terminal fragment of CITED2 (224243) and a C-terminal fragment of HIF-1a (792-826) fragment. Expressed and chemically synthesized peptides were tested with both giving a $K_{D}$ slightly higher than the HIF-1 $\alpha$ sequences and comparable to the CITED2 sequences (Table 2). A fluorescence anisotropy competition assay established that this hybrid sequence competes with HIF-1a for binding to p300, supporting the hypothesis that CITIF reproduces key binding features of both HIF-1a and CITED2 (Fig. S9). Whilst both the HIF-1a sequences were shown to have strongly favourable p300 binding enthalpies and strongly unfavourable p300 binding entropies, in contrast, both CITED2 sequences were shown to have much less favourable p300 binding enthalpies, and much less unfavourable p300 binding entropies. The CITIF sequence exhibited p300 binding enthalpies and entropies intermediate between those observed for HIF-1 $\alpha$ and CITED2. We obtained co-crystals of p300 in complex with CITIF and solved the structure at $2 \AA$ resolution (Fig. 6 , Table S3). The structure shows that residues corresponding to CITED2 and HIF-1 $\alpha$ bind simultaneously, occupying their native binding sites and reproducing most of the native contacts with the protein (Fig S11.), in line with the thermodynamic signature we observed for CITIF binding. Similarly to the CITED2-HIF-1 $\alpha$ fusion peptide/CBP complex (PDB: 7LVS, Fig S12) recently reported by Appling et al., the Nterminal p300 ${ }_{345-373}$ helix $\left(\alpha_{1}\right)$ is straightened compared to the CITED2/p300 and HIF-1 $\alpha$ /P300 
binary complexes and the C terminus of CITIF (corresponding to HIF-1 $\alpha_{815-826}$ ) is not fully folded, which might be due to the allosteric effects of CITED2 residues binding.

(a)

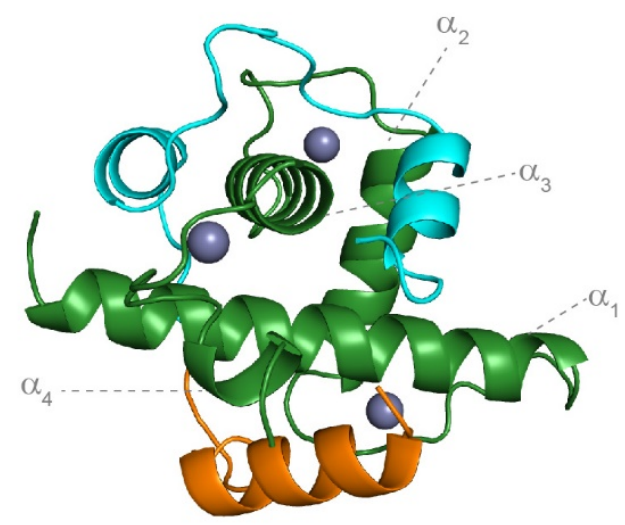

(b)

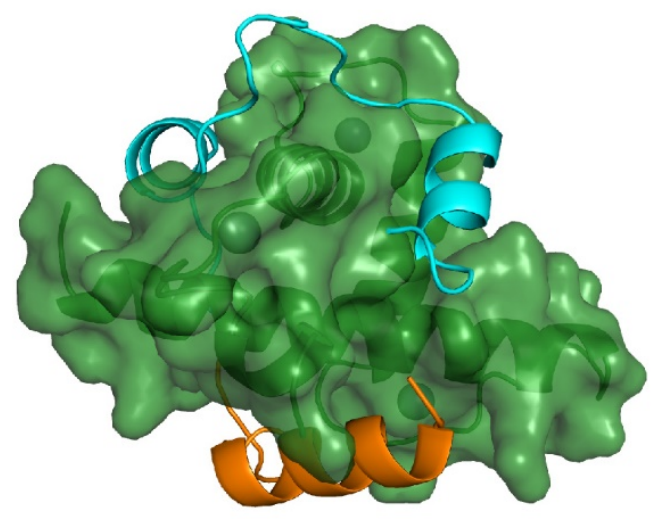

Figure 6. Crystal structure of p300 (green) in complex with CITIF determined at $2 \AA$ resolution (PDB: 7QGS). Residues corresponding to CITED2 $224-243$ are coloured orange, residues corresponding to HIF-1 $\alpha_{792-826}$ are coloured cyan.

These data show that CITED2 $224-243$ and HIF-1 $\alpha_{792-826}$ sequences can bind simultaneously to p300 without interfering with one another, further supporting the hypothesis of the ternary complex formation, and suggesting that these sequences may not contain the key components that induce unidirectional displacement of HIF-1a, by CITED2. Berlow et al. previously used ${ }^{1} \mathrm{H}-{ }^{15} \mathrm{~N}$ NOE experiments to identify significant differences in the degree of dynamic disorder and therefore flexibility between $\mathrm{p} 300$ bound ${ }^{15} \mathrm{~N}$ HIF-1 $1 \alpha$ and ${ }^{15} \mathrm{~N}$ CITED2. ${ }^{46} \mathrm{HIF}-1 \alpha$ was shown to display a wide range of dynamics throughout its sequence with both ordered and flexible regions, notably in the LPQL motif which was shown to play a role in the binding mechanism. CITED2 on the other hand elicited more uniform behaviour consistent with a more ordered structure. Subsequently Appling et al. used a HIF-1 $\alpha$-CITED2 fusion peptide similar to the one reported here to probe further the binding mechanism; these studies revealed that the region corresponding to HIF-1 $\alpha_{815-826}$ and the region corresponding to the CITED2 $224-235$ are mutually destabilizing to one another and this negative allostery is governed by the length and 
orientation of the C-terminal p300 helix $\left(\alpha_{4}\right) .{ }^{47}$ Molecular dynamics simulations also identified a HIF-1a/CITED2/p300 ternary complex in support of this model and point to a role for hydrophobic residues C-terminal to the LPEL residues as being important in displacing the HIF-1 $\alpha_{797-805}$ helix. ${ }^{61-63}$ Similarly, ${ }^{15} \mathrm{~N}$-relaxation and side chain methyl ${ }^{2} \mathrm{H}$-relaxation experiments on p300 and side chain methyl ${ }^{2} \mathrm{H}$-relaxation for bound HIF-1 $\alpha$ demonstrated (i) that side-chain and backbone dynamics for p300 upon binding to CTAD-HIF-1a involve an unfavourable conformational entropy change on complex formation (with the backbone contribution dominant), (ii) that HIF-1a similarly undergoes a significant side chain conformational entropy change upon p300 recognition and (iii) the N-terminal region of HIF$1 \alpha$, the residues in p300 contacting the LPQL motif and the C-terminus of p300 remain dynamic when bound. ${ }^{64}$ Finally, comparative in silico alanine scanning results (Figure S10) determined using BAlaS ${ }^{56}$ (a web-based server version of BudeAlaScan) for HIF-1a/p300 (PDB ID: 1L8C), CITED2/p300 (PDB ID: 1P4Q) and the CITED-HIF-fusion/CBP complex (PDB ID: 7LVS) reported by Appling et al. show a dispersed distribution of potential hot residues (similar to that observed for HIF-1a/p300 (PDB ID: 1L8C) using BudeAlaScan), but with a greater proportion towards the N-terminus in CITED2 and the C-Terminus in HIF-1a. The variation of one of these hot residues (L63A) in the CITED2-HIF-1 $\alpha$ fusion peptide corresponding to L822A in this work) resulted in the complete displacement of the $\mathrm{C}$ terminal HIF-1 $\alpha_{815-826}$ helix which allowed the binding of the $N$ terminal helix of the fusion peptide (corresponding to CITED2 $216-246$ ). ${ }^{47}$ This implies that although individual variations do not have a significant effect on overall binding affinity they can be important mechanistically in mediating allosteric responses. Our ITC experiments can be rationalized in the context of these data; strongly favourable p300 binding enthalpies, and strongly unfavourable p300 binding

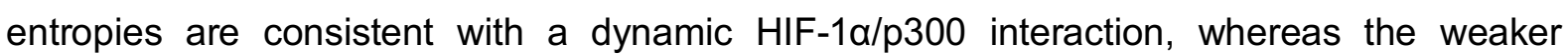
enthalpies and entropies of interaction are consistent with a more ordered CITED2/p300 interaction. Crucially where CITIF is concerned, the N-terminal fragment of CITED2224-243 is derived from a region that is highly ordered in the CITED/p300 interaction and so the observed enthalpy-entropy compensation might be excepted for CITIF which marries the N-terminus of CITED2 with the C-Terminus of HIF-1a. Overall, the results are fully consistent with the sequence variation studies described above in which variants with a significant predicted $\Delta \Delta G$ were observed to bind with comparable affinity, less favourable enthalpy and more favourable entropy when compared to the parent sequence. Taken together, the results underscore recent observations on the protein-protein interactions of intrinsically disordered regions in which sequence variation has limited impact on binding affinity; ${ }^{65-66}$ enthalpy-entropy compensation provides the scope for such fuzzy interactions to accommodate sequence variation without significant impact on binding affinity and therefore function. 


\section{Conclusions}

We have shown using a combination of single and multiple alanine sequence variants of HIF$1 \alpha$ alongside sequence hybrids with the negative regulator of HIF-1 $\alpha$ (CITED2) that interaction with p300 is highly tolerant to sequence variation as demonstrated by fluorescence anisotropy and isothermal titration calorimetry. Recent studies on the interaction of p300(CBP) with HIF$1 \alpha$ or CITED2 have largely focussed on dynamic structural studies and molecular dynamics simulations to rationalise the displacement of HIF-1 $\alpha$ from p300 by CITED2. 40, 46-47, 53, 61-64 Our equilibrium measurements for a range of sequence variants provide complementary data demonstrating interaction between HIF-1 $\alpha$ and p300 is characterized by a large favourable enthalpy and large unfavourable entropy of binding. The absence of dramatic changes in binding affinity for alanine variants taken together with an observed enthalpy-entropy compensation is consistent with significant chelate co-operativity ${ }^{21,50}$ and dispersal of binding energy across the sequence, with binding free energy derived from non-covalent contacts between the HIF-1 $\alpha$ backbone (in addition to side-chains) and the surface of the p300 $\mathrm{CH} 1$ domain, alongside favourable long range electrostatic and transient side-chain interactions during HIF-1a folding. Such behaviour provides a mechanism for the intrinsically disordered HIF-1 $\alpha$ sequence to tolerate sequence variation by adopting a more disordered bound state in its interaction with p300. Binding of CITED2 to p300 however is characterized by small favourable enthalpy and entropy changes, yet (in our hands) its affinity for p300 is slightly higher than that of HIF-1 $\alpha$ and therefore may also augment the allosteric changes that accompany ternary complex formation between HIF-1a, CITED2 and p300 en route to unidirectional displacement of HIF-1 $\alpha$ by CITED2. Such behaviour is encompassed in CITIF,

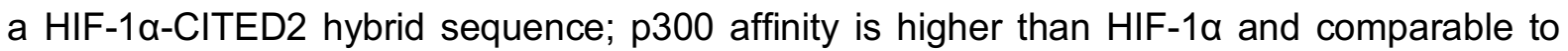
CITED2, with a thermodynamic signature that is intermediate between the two representing a consonance between the high affinity less dynamic CITED2 sequence and the more fuzzy HIF-1a. This and the sequence dependent competition mechanism by which the negative feedback regulator CITED2 displaces HIF-1 a may provide insight to inform design of selective HIF-1a modulators. More broadly, these results underscore the advantageous features of intrinsically disordered regions in facilitating function ${ }^{67-68}$ whilst such sequence tolerance may represent an additional rational for the prevalence of disease relevant mutations within intrinsically disordered regions. ${ }^{69}$

\section{Declarations of interest}

The authors declare no competing financial interests. 


\section{Acknowledgements}

We would like to thank Dr lain Manfield for his support with ITC measurements and ongoing collaboration with AstraZeneca, Domainex and the Northern Institute for Cancer Research. We would like to thank $\mathrm{Dr}$ Chi H. Trinh for his support with crystallography. We acknowledge Diamond Light Source for time on Beamline 104 under Proposal mx19248 and the authors would like to thank the staff of this beamline for assistance with data collection.

\section{Funding information}

This work was supported by EPSRC (EP/N013573/1 and EP/KO39292/1) and the BBSRC/EPSRC-funded Synthetic Biology Research Centre, BrisSynBio (BB/L01386X/1). This project has received funding from the European Union's Horizon 2020 research and innovation programme under the Marie Skłodowska-Curie grant agreement no. MSCA-IF2016-749012. Z.H. received funding from the National Research, Development and Innovation Office - NKFIH PD 135324. A. J. W. wishes to acknowledge the support of a Royal Society Leverhulme Trust Senior Fellowship (SRF\R1\191087)

\section{Author contribution statement}

Z. H., A.J.W. and T. A. E. conceived and designed the research program, F. H and Z. H. designed studies and performed the research with support from A. A. I., V. L. P., G. J. B, and R. B. S. The manuscript was written by F. H, and Z. H. and edited into its final form by A.J.W. and T.A.E with contributions from all authors.

\section{References}

1. Vaupel, P.; Thews, O.; Kelleher, D. K.; Hoeckel, M., Current Status of Knowledge and Critical Issues in Tumor Oxygenation. In Oxygen Transport to Tissue XX. Hudetz, A. G.; Bruley, D. F., Eds. Springer US: Boston, MA, 1998; pp 591-602.

2. Manalo, D. J.; Rowan, A.; Lavoie, T.; Natarajan, L.; Kelly, B. D.; Ye, S. Q.; Garcia, J. G. N.; Semenza, G. L., Transcriptional regulation of vascular endothelial cell responses to hypoxia by HIF-1. Blood 2005, 105 (2), 659-669.

3. Semenza, G. L., Oxygen Sensing, Homeostasis, and Disease. New England Journal of Medicine 2011, 365 (6), 537-547.

4. Hanahan, D.; Weinberg, Robert A., Hallmarks of Cancer: The Next Generation. Cell 2011, 144 (5), 646-674.

5. Semenza, G. L., Signal transduction to hypoxia-inducible factor 1. Biochem. Pharmacol. 2002, 64 (5-6), 993-998.

6. Pugh, C. W.; Ratcliffe, P. J., Regulation of angiogenesis by hypoxia: role of the HIF system. Nat. Med. 2003, 9 (6), 677-684. 
bioRxiv preprint doi: https://doi.org/10.1101/2021.12.16.472944; this version posted December 16, 2021. The copyright holder for this preprint (which was not certified by peer review) is the author/funder, who has granted bioRxiv a license to display the preprint in perpetuity. It is made available under aCC-BY-ND 4.0 International license.

7. Huang, L. E.; Bunn, H. F., Hypoxia-inducible Factor and Its Biomedical Relevance. J. Biol. Chem. 2003, 278 (22), 19575-19578.

8. Semenza, G. L., Targeting HIF-1 for cancer therapy. Nat. Rev. Cancer 2003, 3 (10), 721 732.

9. Semenza, G. L., Defining the role of hypoxia-inducible factor 1 in cancer biology and therapeutics. Oncogene 2009, 29 (5), 625-634.

10. Nordgren, I. K.; Tavassoli, A., Targeting tumour angiogenesis with small molecule inhibitors of hypoxia inducible factor. Chem. Soc. Rev. 2011, 40 (8), 4307-4317.

11. Burslem, G. M.; Kyle, H. F.; Nelson, A.; Edwards, T. A.; Wilson, A. J., Hypoxia inducible factor (HIF) as a model for studying inhibition of protein-protein interactions. Chem. Sci. 2017, 8 (6), 4188-4202.

12. Martin, A. R.; Ronco, C.; Demange, L.; Benhida, R., Hypoxia inducible factor downregulation, cancer and cancer stem cells (CSCs): ongoing success stories. MedChemComm 2017, 8 (1), 21-52.

13. Kung, A. L.; Zabludoff, S. D.; France, D. S.; Freedman, S. J.; Tanner, E. A.; Vieira, A.; Cornell-Kennon, S.; Lee, J.; Wang, B.; Wang, J.; Memmert, K.; Naegeli, H.-U.; Petersen, F.; Eck, M. J.; Bair, K. W.; Wood, A. W.; Livingston, D. M., Small molecule blockade of transcriptional coactivation of the hypoxia-inducible factor pathway. Cancer Cell 2004, 6 (1), 33-43.

14. Cook, K. M.; Hilton, S. T.; Mecinovic, J.; Motherwell, W. B.; Figg, W. D.; Schofield, C. J., Epidithiodiketopiperazines Block the Interaction between Hypoxia-inducible Factor- $1 \hat{I} \pm$ (HIF-1 Ît) and p300 by a Zinc Ejection Mechanism. J. Biol. Chem. 2009, 284 (39), 2683126838.

15. Henchey, L. K.; Kushal, S.; Dubey, R.; Chapman, R. N.; Olenyuk, B. Z.; Arora, P. S., Inhibition of hypoxia inducible factor 1-transcription coactivator interaction by a hydrogen bond surrogate a-helix. J. Am. Chem. Soc. 2010, 132 (3), 941-943.

16. Miranda, E.; Nordgren, I. K.; Male, A. L.; Lawrence, C. E.; Hoakwie, F.; Cuda, F.; Court, W.; Fox, K. R.; Townsend, P. A.; Packham, G. K.; Eccles, S. A.; Tavassoli, A., A Cyclic Peptide Inhibitor of HIF-1 Heterodimerization That Inhibits Hypoxia Signaling in Cancer Cells. J. Am. Chem. Soc. 2013.

17. Kushal, S.; Lao, B. B.; Henchey, L. K.; Dubey, R.; Mesallati, H.; Traaseth, N. J.; Olenyuk, B. Z.; Arora, P. S., Protein domain mimetics as in vivo modulators of hypoxia-inducible factor signaling. Proc. Natl. Acad. Sci. U. S. A. 2013, 110 (39), 15602-15607.

18. Burslem, G. M.; Kyle, H. F.; Breeze, A. L.; Edwards, T. A.; Nelson, A.; Warriner, S. L.; Wilson, A. J., Small-Molecule Proteomimetic Inhibitors of the HIF-1a-p300 ProteinProtein Interaction. ChemBioChem 2014, 15 (8), 1083-1087.

19. Lao, B. B.; Grishagin, I.; Mesallati, H.; Brewer, T. F.; Olenyuk, B. Z.; Arora, P. S., In vivo modulation of hypoxia-inducible signaling by topographical helix mimetics. Proc. Natl. Acad. Sci. U. S. A. 2014, 111 (21), 7531-7536.

20. Lao, B. B.; Drew, K.; Guarracino, D. A.; Brewer, T. F.; Heindel, D. W.; Bonneau, R.; Arora, P. S., Rational Design of Topographical Helix Mimics as Potent Inhibitors of ProteinProtein Interactions. J. Am. Chem. Soc. 2014, 136 (22), 7877-7888.

21. Burslem, G. M.; Kyle, H. F.; Breeze, A. L.; Edwards, T. A.; Nelson, A.; Warriner, S. L.; Wilson, A. J., Towards "bionic" proteins: replacement of continuous sequences from HIF$1 \alpha$ with proteomimetics to create functional p300 binding HIF-1 $\alpha$ mimics. Chem. Commun. 2016, 52 (31), 5421-5424.

22. Mistry, I. N.; Tavassoli, A., Reprogramming the Transcriptional Response to Hypoxia with a Chromosomally Encoded Cyclic Peptide HIF-1 Inhibitor. ACS Synth. Biol. 2016.

23. Hetherington, K.; Hegedus, Z.; Edwards, T. A.; Sessions, R.; Nelson, A.; Wilson, A. J., Stapled Peptides as HIF-1a/p300 Inhibitors: Helicity Enhancement in the Bound State Increases Inhibitory Potency. Chem. Eur. J. 2020, 26 (n/a), 7638-7646.

24. Qin, X.; Chen, H.; Tu, L.; Ma, Y.; Liu, N.; Zhang, H.; Li, D.; Riedl, B.; Bierer, D.; Yin, F.; $\mathrm{Li}, \mathrm{Z}$., Potent Inhibition of HIF1a and p300 Interaction by a Constrained Peptide Derived from CITED2. J. Med. Chem. 2021, 64 (18), 13693-13703. 
25. Arany, Z.; Huang, L. E.; Eckner, R.; Bhattacharya, S.; Jiang, C.; Goldberg, M. A.; Bunn, H. F.; Livingston, D. M., An essential role for p300/CBP in the cellular response to hypoxia. Proc. Natl. Acad. Sci. U. S. A. 1996, 93 (23), 12969-12973.

26. Ivan, M.; Kondo, K.; Yang, H.; Kim, W.; Valiando, J.; Ohh, M.; Salic, A.; Asara, J. M.; Lane, W. S.; Kaelin Jr., W. G., HIFa Targeted for VHL-Mediated Destruction by Proline Hydroxylation: Implications for O2 Sensing. Science 2001, 292 (5516), 464-468.

27. Jaakkola, P.; Mole, D. R.; Tian, Y. M.; Wilson, M. I.; Gielbert, J.; Gaskell, S. J.; von Kriegsheim, A.; Hebestreit, H. F.; Mukherji, M.; Schofield, C. J.; Maxwell, P. H.; Pugh, C. W.; Ratcliffe, P. J., Targeting of HIF-alpha to the von Hippel-Lindau ubiquitylation complex by O2-regulated prolyl hydroxylation. Science 2001, 292 (5516), 468-72.

28. Dames, S. A.; Martinez-Yamout, M.; De Guzman, R. N.; Dyson, H. J.; Wright, P. E., Structural basis for Hif-1 $\alpha /$ CBP recognition in the cellular hypoxic response. Proc. Natl. Acad. Sci. U. S. A. 2002, 99 (8), 5271-5276.

29. Powis, G.; Kirkpatrick, L., Hypoxia inducible factor-1a as a cancer drug target. Mol. Cancer Ther. 2004, 3 (5), 647-654.

30. Wu, D.; Potluri, N.; Lu, J.; Kim, Y.; Rastinejad, F., Structural integration in hypoxiainducible factors. Nature 2015, 521 (7565), 303-308.

31. Vo, N.; Goodman, R. H., CREB-binding Protein and p300 in Transcriptional Regulation. J. Biol. Chem. 2001, 276 (17), 13505-13508.

32. Wang, F.; Marshall, C.; Ikura, M., Transcriptional/epigenetic regulator CBP/p300 in tumorigenesis: structural and functional versatility in target recognition. Cellular and Molecular Life Sciences 2013, 70 (21), 3989-4008.

33. Freedman, S. J.; Sun, Z.-Y. J.; Poy, F.; Kung, A. L.; Livingston, D. M.; Wagner, G.; Eck, M. J., Structural basis for recruitment of CBP/p300 by hypoxia-inducible factor-1a. Proc. Natl. Acad. Sci. U. S. A. 2002, 99 (8), 5367-5372.

34. De Guzman, R. N.; Wojciak, J. M.; Martinez-Yamout, M. A.; Dyson, H. J.; Wright, P. E., CBP/p300 TAZ1 Domain Forms a Structured Scaffold for Ligand Binding †, $\ddagger$. Biochemistry 2004, 44 (2), 490-497.

35. Freedman, S. J.; Sun, Z.-Y. J.; Kung, A. L.; France, D. S.; Wagner, G.; Eck, M. J., Structural basis for negative regulation of hypoxia-inducible factor-1 $\alpha$ by CITED2. Nat. Struct. Mol. Biol. 2003, 10 (7), 504-512.

36. De Guzman, R. N.; Martinez-Yamout, M. A.; Dyson, H. J.; Wright, P. E., Interaction of the TAZ1 Domain of the CREB-Binding Protein with the Activation Domain of CITED2: Regulation by competition between intrinsically unstructured ligands for non-identical binding sites*. J. Biol. Chem. 2004, 279 (4), 3042-3049.

37. Krois, A. S.; Ferreon, J. C.; Martinez-Yamout, M. A.; Dyson, H. J.; Wright, P. E., Recognition of the disordered p53 transactivation domain by the transcriptional adapter zinc finger domains of CREB-binding protein. Proc. Natl. Acad. Sci. U. S. A. 2016, 113 (13), E1853-E1862.

38. Mukherjee, S. P.; Behar, M.; Birnbaum, H. A.; Hoffmann, A.; Wright, P. E.; Ghosh, G., Analysis of the RelA:CBP/p300 Interaction Reveals Its Involvement in NF-kB-Driven Transcription. PLoS Biol. 2013, 11 (9), e1001647.

39. Wojciak, J. M.; Martinez-Yamout, M. A.; Dyson, H. J.; Wright, P. E., Structural basis for recruitment of CBP/p300 coactivators by STAT1 and STAT2 transactivation domains. The EMBO Journal 2009, 28 (7), 948-958.

40. Gao, M.; Yang, J.; Liu, S.; Su, Z.; Huang, Y., Intrinsically Disordered Transactivation Domains Bind to TAZ1 Domain of CBP via Diverse Mechanisms. Biophys. J. 2019, 117 (7), 1301-1310.

41. Bhattacharya, S.; Michels, C. L.; Leung, M.-K.; Arany, Z. P.; Kung, A. L.; Livingston, D. M., Functional role of p35srj, a novel p300/CBP binding protein, during transactivation by HIF-1. Genes Dev. 1999, 13 (1), 64-75.

42. Yin, Z.; Haynie, J.; Yang, X.; Han, B.; Kiatchoosakun, S.; Restivo, J.; Yuan, S.; Prabhakar, N. R.; Herrup, K.; Conlon, R. A.; Hoit, B. D.; Watanabe, M.; Yang, Y.-C., The essential role of Cited2, a negative regulator for HIF-1a, in heart development and neurulation. Proc. Natl. Acad. Sci. U. S. A. 2002, 99 (16), 10488-10493. 
43. Xu, B.; Doughman, Y.; Turakhia, M.; Jiang, W.; Landsettle, C. E.; Agani, F. H.; Semenza, G. L.; Watanabe, M.; Yang, Y.-C., Partial rescue of defects in Cited2-deficient embryos by HIF-1a heterozygosity. Dev. Biol. 2007, 301 (1), 130-140.

44. Shin, D. H.; Li, S. H.; Chun, Y. S.; Huang, L. E.; Kim, M. S.; Park, J. W., CITED2 mediates the paradoxical responses of HIF-1a to proteasome inhibition. Oncogene 2008, 27 (13), 1939-1944.

45. Henze, A.-T.; Acker, T., Feedback regulators of hypoxia-inducible factors and their role in cancer biology. Cell Cycle 2010, 9 (14), 2821-2835.

46. Berlow, R. B.; Dyson, H. J.; Wright, P. E., Hypersensitive termination of the hypoxic response by a disordered protein switch. Nature 2017, 543 (7645), 447-451.

47. Appling, F. D.; Berlow, R. B.; Stanfield, R. L.; Dyson, H. J.; Wright, P. E., The molecular basis of allostery in a facilitated dissociation process. Structure 2021, 10.1016/j.str.2021.07.011.

48. Ruas, J. L.; Poellinger, L.; Pereira, T., Functional Analysis of Hypoxia-inducible Factor1a-mediated Transactivation: Identification of amino acid residues critical for transcriptional activation and/or interaction with creb-binding protein. J. Biol. Chem. 2002, 277 (41), 38723-38730.

49. Cho, H.; Ahn, D.-R.; Park, H.; Yang, E. G., Modulation of p300 binding by posttranslational modifications of the C-terminal activation domain of hypoxia-inducible factor-1 1 t. FEBS Lett. 2007, 581 (8), 1542-1548.

50. Kyle, H. F.; Wickson, K. F.; Stott, J.; Burslem, G. M.; Breeze, A. L.; Tiede, C.; Tomlinson, D. C.; Warriner, S. L.; Nelson, A.; Wilson, A. J.; Edwards, T. A., Exploration of the HIF$1 \alpha /$ p300 interface using peptide and Adhiron phage display technologies. Mol. Biosyst. 2015, 11, 2738-2749.

51. Gu, J.; Milligan, J.; Huang, L. E., Molecular Mechanism of Hypoxia-inducible Factor 1ap300 Interaction: A leucine-rich interface regulated by a single cysteine. J. Biol. Chem. 2001, 276 (5), 3550-3554.

52. Lando, D.; Peet, D. J.; Whelan, D. A.; Gorman, J. J.; Whitelaw, M. L., Asparagine Hydroxylation of the HIF Transactivation Domain: A Hypoxic Switch. Science 2002, 295 (5556), 858-861.

53. Lindström, I.; Andersson, E.; Dogan, J., The transition state structure for binding between TAZ1 of CBP and the disordered Hif-1a CAD. Sci. Rep. 2018, 8 (1), 7872.

54. Lindström, I.; Dogan, J., Native Hydrophobic Binding Interactions at the Transition State for Association between the TAZ1 Domain of CBP and the Disordered TAD-STAT2 Are Not a Requirement. Biochemistry 2017, 56 (32), 4145-4153.

55. Burslem, G. M.; Kyle, H. F.; Prabhakaran, P.; Breeze, A. L.; Edwards, T. A.; Warriner, S. L.; Nelson, A.; Wilson, A. J., Synthesis of highly functionalized oligobenzamide proteomimetic foldamers by late stage introduction of sensitive groups. Org. Biomol. Chem. 2016, 14 (15), 3782-3786.

56. Wood, C. W.; Ibarra, A. A.; Bartlett, G. J.; Wilson, A. J.; Woolfson, D. N.; Sessions, R. B., BAlaS: fast, interactive and accessible computational alanine-scanning using BudeAlaScan. Bioinformatics 2020, 36, 2917-2919.

57. Ibarra, A. A.; Bartlett, G. J.; Hegedüs, Z.; Dutt, S.; Hobor, F.; Horner, K. A.; Hetherington, K.; Spence, K.; Nelson, A.; Edwards, T. A.; Woolfson, D. N.; Sessions, R. B.; Wilson, A. J., Predicting and Experimentally Validating Hot-Spot Residues at Protein-Protein Interfaces. ACS Chem. Biol. 2019, 14 (10), 2252-2263.

58. Clackson, T.; Wells, J., A hot spot of binding energy in a hormone-receptor interface. Science 1995, 267 (5196), 383-386.

59. London, N.; Raveh, B.; Schueler-Furman, O., Druggable protein-protein interactions from hot spots to hot segments. Curr. Opin. Chem. Biol. 2013, 17 (6), 952-959.

60. Kim, D. E.; Chivian, D.; Baker, D., Protein structure prediction and analysis using the Robetta server. Nucleic Acids Res. 2004, 32 (suppl_2), W526-W531.

61. Wang, Y.; Brooks III, C. L., Electrostatic Forces Control the Negative Allosteric Regulation in a Disordered Protein Switch. J. Phys. Chem. Lett. 2020, 11 (3), 864-868. 
62. Chu, W.-T.; Chu, X.; Wang, J., Investigations of the underlying mechanisms of HIF-1a and CITED2 binding to TAZ1. Proc. Natl. Acad. Sci. U. S. A. 2020, 117 (11), 5595-5603.

63. Ruiz-Ortiz, I.; De Sancho, D., Competitive binding of HIF-1 $\alpha$ and CITED2 to the TAZ1 domain of CBP from molecular simulations. Physical Chemistry Chemical Physics 2020, 22 (15), 8118-8127.

64. Nyqvist, I.; Dogan, J., Characterization of the dynamics and the conformational entropy in the binding between TAZ1 and CTAD-HIF-1a. Sci. Rep. 2019, 9 (1), 16557.

65. Warfield, L.; Tuttle, L. M.; Pacheco, D.; Klevit, R. E.; Hahn, S., A sequence-specific transcription activator motif and powerful synthetic variants that bind Mediator using a fuzzy protein interface. Proc. Natl. Acad. Sci. U. S. A. 2014, 111 (34), E3506-E3513.

66. Henley, M. J.; Linhares, B. M.; Morgan, B. S.; Cierpicki, T.; Fierke, C. A.; Mapp, A. K., Unexpected specificity within dynamic transcriptional protein-protein complexes. Proc. Natl. Acad. Sci. U. S. A. 2020, 117 (44), 27346-27353.

67. Shammas, S. L., Mechanistic roles of protein disorder within transcription. Curr. Opin. Struct. Biol. 2017, 42, 155-161.

68. Pricer, R.; Gestwicki, J. E.; Mapp, A. K., From Fuzzy to Function: The New Frontier of Protein-Protein Interactions. Acc. Chem. Res. 2017, 50 (3), 584-589.

69. Vacic, V.; lakoucheva, L. M., Disease mutations in disordered regions-exception to the rule? Mol. Biosyst. 2012, 8 (1), 27-32. 